\title{
Allegories of Passing in Bill T. Jones
}

\author{
Randy Martin
}

A s we move we change. How could it be otherwise? The direction and consequence of change is far from assured. Dance inscribes movement in the world as a practical accomplishment. It legibly affirms, even if ephemerally, fleetingly, that some immediate difference has been made when the outcome of movement in life might still be in doubt. As a means for registering what movement can be, dance shows us how we pass from one state to another. It does this literally, as bodies configure their realms of space and time, and allegorically, as a touchstone to what it means to be passing through this world. Dance reports on the art of passing, telling us how to dwell amongst so many departures and arrivals. It also instructs us in passing as self-representation, convincing us in performance that it is dancers we see. Such a lovely tale, this. Yet in a nation of immigrants, all are compelled to move, but not all get to pass. Those who lived by the land were evicted in the name of property. Those who were designated property were affixed to the land in bondage. Others worked off their debts of passage. Still more were promised mobility from migration.

Out of these mass movements a social compact of immigration, race, and class was constructed. Braided together they shared an imaginary of passing that omitted consideration of what was lost in route. Assimilation would translate cultural distance into upward mobility. Passing from one movement state to another would achieve the choreography of the nation. Always of dubious accuracy, the past several decades have made it difficult to detect the truth of this fable as well, even as the very elastic notion of passing captures the phenomenology of the shifts in policy from welfare-state entitlements to accountability-driven risk management. Where passing once referred to achieving the appearance of normalcy by hiding what one was, it has come to reference demands for standards that can never be met. Historically, dance has played its part in affirming, complicating,

Randy Martin, professor of art and public policy and director of the graduate program in arts politics at New York University, has published a number of books, most recently An Empire of Indifference: American War and the Financial Logic of Risk Management (Duke University Press, 2007), The Returns of Alwin Nikolais: Bodies, Boundaries and the Dance Canon, edited with Claudia Gitelman (Wesleyan University Press, 2007), and Artistic Citizenship: A Public Voice for the Arts, edited with Mary Schmidt Campbell (Routledge, 2006). 
multiplying, and countering the national mythos. It continues to do so today. Given the difficulty in discerning what follows assimilation's failures and recognizing what dance allows us to recognize in the ways of passing, we are wise to pay close attention to those instances that provide the greatest critical insight.

Assimilation as a migration vehicle offers a recipe for the disappearance of difference through the promise that the passengers would achieve citizenship with all the attendant rewards of belonging to the wealthiest among nations. Increasingly the state of security associated with citizenship is being removed such that the endpoint of assimilation, always partial and exclusionary, is itself fading as a construct and a practical opportunity. The assimilationist road was a one-way street with passing poised as a form of loss, a new life wrought through social death. As assimilation itself passes, what other prospects open for the fateful relation between the many and the we? If a unitary point of arrival and unidirectional route loosen their grip on collective migrations, passing now assumes a productive ambiguity. The question remains, how do we move on? Dance offers insight into the techniques and methods of passing; it teaches us how to move in many directions with multiple histories of the body. Like passing itself in a more critical guise, dance can re-incorporate what has been left out or behind, what opens laterally and beyond, what gives pause to its fullness and unclots the narrow passages that obtrude historical transformation. Dance offers many methods of passing that materialize tangibly on stage. While dancers, choreographers, audience, critics, producers, technicians-in short, all the people in the world of dance-come with myriad thoughts and feelings, intentions and aspirations, the ways in which dance bears social, political, and historical prospects slices through persons, places, and worlds so as to momentarily conjoin them in what could be called choreographic agency. The story of these stories, the recounting and valuing of these techniques, is what is meant here by an allegory of passing.

The braiding together of social and choreographic movement, the transposition of migration from theme to analytic operation, forms a transection or conjuncture in which some of dance makes legible certain features of society. As a term of description and account, "passing" undertakes this double duty. The immigrant without legal documentation is caught in an economy of passing where the very jobs that occasioned their movement and legitimate their presence within the country can suddenly become illicit activities. Racial passing has long been a feature of cultural representation, with very uneven movement between what it means to pass as white and what is entailed by stylized appropriations of black or Latino identity, especially with respect to the pleasures of popular culture. The figure of a middle class-neither rich nor poor-has stood for a passage from a world of labor subordinated to others to consumption in a domestic sphere over which one claims mastery. Self-appointment to the middle class enables disavowal of being a worker while justifying a life of toil that affords participation in the bounty of the American dreamscape. We might say that all of these assimilationist parables have been put under pressure by the tropes and policies that constitute various domestic wars-race wars, immigrant wars, and now the war on the middle class.

The conversion of domestic policy from a realm of entitlements to one modeled on war (as the ultimate form of risk management in the face of lost security) has been in process 
over the course of nearly thirty years, a span that corresponds to the career of Bill T. Jones. While there is no singular manner in which an artist relates to an historical surround, some bodies of work provide singular insight into their times. At crucial moments in his choreographic itinerary, Jones has engaged the epic and the allegorical in a manner that makes legible features of the political moment. More specifically, his choreographic oeuvre is replete with the art of passing. I would like to read these allegories of passing across several significant choreographic works to see what they tell us about an artistic negotiation with a historical conjuncture. The works that I will focus on are D-man in the Waters (I989); Last Supper at Uncle Tom's Cabin (1990); Still/Here (1994); Another Evening: I Bow Down (2006); and Chapel/Chapter (2006). I want to look both inside and across these works for what they can disclose about an historical problematic and how Jones has complicated the prevalent narratives of passing in his being framed by and re-framing the moniker "victim-art." I also want to examine the different ways in which Jones positions his audience address as a way of reflecting upon what constitutes a political voicing within the current public sphere. In the end, I hope that this work with Jones can enable us to reflect upon the expectations of passing that the arts are now placed under and what strategies we might devise to critically engage these mastering tropes.

Among choreographers of contemporary concert dance, Bill T. Jones is exceptionally successful, ambitious, prolific, and public. For all his renown and achievement, his career jostles any conventional notions of assimilation. Born on February 15, 1952, the tenth of twelve children in a family of migrant farm workers in upstate Steuben County, New York, his life began very far away from where he would end up. And yet the rich lodes of African American storytelling, the sense of being at the heart of a community, even the itinerant existence shared by touring dancer and agricultural laborer continue to appear in his work. Upstate New York in the ig6os was also a bedrock of counter-cultural expressions like Woodstock, where Jones went with his brother Azel. Black power was asserted at Attica and the takeover of the student union at Cornell in ig69. He met Arnie Zane, son of a Brazilian father and Lithuanian mother, at the State University of New York (SUNY) in Binghamton in 1971. Their work and lives together launched him into the New York dance and cultural scene. Zane's passing at his Valley Cottage home in 1988 is marked by a persistent presence in the Bill T. Jones/Arnie Zane Dance Company but also by what endures as a profoundly anti-assimilationist meaning of the term "passing." The AIDS virus that ravaged Zane's body and that had such a devastating effect on the dance community also figured in the cultural conflicts of the day as a kind of social death. The conservative reaction to AIDS carried more than the moralism of victim-blaming. It signaled the limit to death as the private passage of the self, and transformed it into a social phenomenon whose risk factors would be understood along the lines of warfare. Queer sexuality challenged not simply the normalized partnerships but the very sequestering of pleasure in the invisibility of the private sphere where, in assimilationist terms, cultural difference of any sort was to reside. The neoconservative culture wars were waged on this same terrain of making the private public, of marshaling state forces of coercion and punitive removals of government funding, as those they attacked. Through a complex conjuncture of forces, the dance boom that launched Jones's career was a salvo across that very bow. 
Domestic policy initiatives of the Reagan years-and extending to the present daydeployed the category of "at-risk" to describe all manner of person and conduct thought to compromise the security of the nation by diminishing its ability to reign supreme in the world. War was not simply a metaphor for this enemy within. Rather, the declaration of war against poorly achieving students, single mothers on welfare, drug users, criminals, queers, artists, and other strangers authorized the federalization of law enforcement that brought to bear the coercive arm of the state once gloved behind assimilationist protocols of defined benefits and equal opportunity. Where once citizenship offered these rewards to migrants and the home born who passed muster, the domestic wars against the amalgamated categories of the at-risk amounted to a revocation of citizenship without notice, as any person could fall from the risk-capable - those who were good for country and economy-to those who spread bad risk to themselves and others. The dance world that Jones and Zane helped to forge offered a different valuation of risk and refused the cleavage of person and population between the risk-capable and the at-risk. From contact improvisation to the marathon athleticism of a Molissa Fenley or the physical daring of an Elizabeth Streb, or the disquieting confrontations of a Liz Lerman or the probing questions of Jawole Jo Zollar, dance was pressing on the productivities of what bodies can be and do while refusing the victimology and moral panic that insisted that some need be forgotten and left behind. Jones emerged from the cauldron of domestic conflict with a repertoire and a repertory that redirected without avoiding the baleful economies of risk.

Already with Fever Swamp (1983), initially made for the Alvin Ailey Company, and Secret Pastures (1984) the company showed a maverick combination of vital dancing and suggestive social commentary. $D$-man in the Waters, which became a signature work of the company after Zane's death, was in Jones's own reckoning not about AIDS but rather survival as such under the multiple fronts of assault that the Ig8os introduced. "It's about life throwing down the gauntlet and you rising to the occasion" (Zucker 2000). The dance is named in honor of company member Damien Acquavella, whom Jones dubbed "D-man":

I had a daydream, almost a vision, in which I saw Damien and a myriad of friends, living and dead, in a body of water. Perhaps it was a lake as vast as the ocean, a lake emptied by an immense and unforgiving waterfall. This company of people was struggling against the current. Some had already drowned, others where grasping their comrades to save them, still others were swimming confidently, almost enjoying their effort. (Jones I995, 194)

By the time the piece premiered in 1989 , Acquavella could not walk, so Jones carried him on stage, "offering my legs as he executed the arm movements of what would have been his solo. When Damien could no longer perform, I chose not to replace him in the piece. Oddly symmetrical groups now mark his absence. Damien passed in June of 1990" (Jones 1995, 194). That the dancers are "enjoying their effort" is amply in evidence at a performance of company work. For all the tragedy of loss and engagement with passing, the energy that the dancers display on stage, the exuberance they emit, and the enthusiasms they generate transform the vulnerabilities under which dance and dancers are placed as categories at-risk into those whose embrace of risk pushes past the stric- 
tures of survival and survivability that frame culture as and in a time of crisis. As dancer Rosalynde Le Blanc remarked describing her own struggle to survive to the end of the dance and fight through her exhaustion, the work places dancers in the predicament they would have us see in the world, as such, that it is a "true life thing in a make-believe world" (Zucker 2000).

In the case of $D$-man, there is considerable wit, humor, and irony, in addition to defying the passing or death of the dance itself. Set to music by Felix Mendelsohn, the piece opens playfully, with dancers running past each other to get to the front of a line that shifts as they assemble it. They add quick scissor-like flipper gestures with their arms before taking a chest dive into the dark pools beyond the dimly lit stage. Time and again, they leap without looking, are caught and returned, chased and escape. Most of the movement flows laterally across the stage with wave upon wave of entrance and exit. For nearly half of the thirty-five-minute dance, performers are swept on and off and no one is able to hold center stage, until a duet quietly resides there. The first part ends with a final daring leap into the void as the stage darkens altogether after an Arthur Aviles plunge. The second part opens with a slow lateral passage in relevé, which morphs into shape-borne partnerings that evoke the meditative bliss of a fake fish tank. Gestural details are lifted from the waters of life, as in one undulating forward hinge that Jones calls "vomiting on 5th Avenue" after a day with Zane at the chemotherapist's office. Graceful sweeps are given counterpoint by tremulous legs, disclosing partially infected bodies. Flailing into the air turns back to self-beating with clenched fists. A duet between Bill T. Jones and Lawrence Goldhubber elicits howls from the audience as unexpected catches and releases take place. In a leap that is a motif across both parts, dancers loft skyward to form a delicate crescent that brings the celestial and the submarine together in transcended depth. Clustered together the company hurtles a lone dancer high into the air. The theater blackens before we ever see him come down.

Despite considerable critical attentions, large audiences at major dance venues like $\mathrm{New}$ York's City Center and the Brooklyn Academy of Music, commissions, and international bookings, the company was, at the end of the 1980 , still financially precarious. While the National Endowment for the Arts (NEA) was made notorious for the vituperative cuts in its already modest budget, its organizational legacy was to insist that choreographers conceive of themselves as corporate heads that would pursue a portfolio of various kinds of support and manage their own financial risks. A large-scale work, once conceivable through a single commission or extended residency, now had to be assembled piece by piece through a patchwork of local investments. Jones's epic reflection on the history and prospect of African American culture in the aftermath of civil rights, Last Supper at Uncle Tom's Cabin/The Promised Land, was constructed by this means of assembly. As Jones saw it, "It was at once taking a bigger risk with the political statements but also more clearly delineating what is form" (Daly 2002, 74). The three-and-a-half-hour work appeared at the height of the NEA controversies and the censorious assault on the speech-acts of multiculturalism that went by the name of political correctness. The double movement between political elaboration and formal refinement struck at the heart of the claims that the two existed outside one another. Not surprisingly, this piece spawned a considerable 
literature in dance studies (Albright 1997; Foster 2002; Goldman forthcoming; R. Martin 1998; Murphy 1995). Ever eloquent on stage and off, Jones could represent himself among these writings as well with a very thorough documentation of the piece's architecture (Jones 1995, 196-223). Here, he articulates his own sense of the nature of his project:

The Promised Land, with its hordes of naked flesh coming wave after wave into the footlights, pubic patches, pert breasts, sagging breasts, wrinkled knees, blissful eyes, furtive expressions of shame, is a visual manifestation of my profound sense of belonging. This was my portrait of us. All of us. And this is who I am too. One of us. It was my battle to disavow any identity as a dying outcast and to affirm our commonality. In it, some one thousand people from thirty cities stood naked, took a bow, and said, "We are not afraid." (Jones 1995, 223)

Jones's effort to portray belonging is at once a refusal to be partitioned into the singularizing identity categories of race, gender, sexuality, and HIV status by which he himself is so commonly referred. Indeed, the piece rejects the simple hierarchy of scale that would separate epic and lyric, the multitude of bodies and narratives assembled and the authorial choreographic vision. Whereas the conventions of passing demand a logic of scarcityout of many comes one, so that all must fit through the eye of a needle to effect a strong thread-the passages that flow through this piece celebrate and insist upon something excessive in our midst. It begins with a journey of a slave ship through the middle passage and moves through an enactment of Harriet Beecher Stowe's Uncle Tom, Sojourner Truth's Aint' I a Woman, and other feints of identity where different dancers appear as the same character (Eliza on the ice), as well as a citation of Amiri Baraka's Dutchman, the tumbling scene of bodies Jones describes above, and a duet of singing and dancing done with his mother, Estella. By so thoroughly imbricating personal and political narrative, and so insistently pressing upon the borders of life stories and social fantasies, Jones provides a manual on passing as a performative achievement that can be accomplished, challenged, and redirected onstage. Jones intends to use everything at his disposal in the service of his art and his politics. "If I am skillful (and I am not always), these words, these gestures can engage, demystify the fearfully unfamiliar, and broaden the ever-evolving social discourse" (Jones 1995, 232).

Four years after Last Supper Jones would produce another work of enormous scale and scope, Still/Here. The piece was noteworthy in its own terms for the range of dance it brought on stage, its vivid juxtaposition/integration of live performance and video, and its use of extensive community workshops with people facing life-threatening illness. Beyond its choreographic prowess, Still/Here garnered more general attention, rare for dance, as an object of public controversy over its critical reception. The episode was initiated by a critic who refused to view the dance and subsequently wrote about it. Through a series of articles, letters, and ongoing discussion, the terms of critical evaluation were themselves opened to scrutiny. The controversy is by now a cause celebre in dance that marks most poignantly the manner in which dance became a front in the culture wars (C. Martin 1996). Beyond a manifest complaint that Jones had transgressed the conventions of artistic representation by bringing actual dying people on stage, the critic, Arlene 
Croce, belied an anxiety that Jones's capacities for self-representation potentially spelled the end of criticism as an autonomous vocation. Croce harkened back to the creation of Fever Swamp a decade before, which Jones had appropriated from one of her own barbs against him.

The critic, like the state, was to have a monopoly on the legitimate use of violence, and Jones's capacity to wear his shame as a kind of naming broke the complicity by which artists can pass muster if they accept their own critical silencing. Dance especially is conventionally slotted as a medium that must be spoken for, for the body is mute and dance must remain faithful to the autonomy of its own ways. For Jones, dance is already spoken for by those who create it; it emerges as it broadens social discourse. In this he will not be assimilated, but nor will his dissidence be allowed to pass. One effect of this war (for its terms were over contending views of social death) was to recast Jones's own work of the late rg9os as a retreat from epic to the lyrical, from the political to the forms-a separation of terms that his work refused when he called for looking with "two sets of eyes" and that perceptive observers continued to see as intercalated (Dent 2005; Goldman forthcoming; Thompson 2005).

Yet the insinuation of bad faith on Jones's part hung heavily. In 2004, as part of a celebration of his twentieth anniversary performing at the Brooklyn Academy of Music (BAM) and a decade after the Croce affair, Jones returned there and restaged parts of StillHere with company members and collaborators he had worked with over the years. In addition, Jones, after years of refusing to make public reference to Croce, reflected on and gave voice to the controversy the earlier performance elicited. This entailed yet a different element of passing, one of moving into one's own history, of refiguring the future as a space of untrammeled innocence into an array of aspirations taken hold of in the present. The publicity for the event remarks on this shift:

In the early eighties, the future was a theoretical, poetic proposition for Bill $\mathrm{T}$. Jones and Arnie Zane. Although Bill kept a journal, he and Arnie had no interest in maintaining repertory. They were interested in the next piece. And, the piece after that. Every piece should be made fresh and new, they believed. When a work outlived its usefulness, it should be allowed to fall away.... "Because our choreographic and theatrical investigation has been broad and evolutionary, any attempt to retrieve a work from the past is like trying to evoke a phantom," says Jones. (Jones 2004)

The confidence in a capacity for eternal innovation, one that eschewed historical encumbrance, is a feature of the modernist temporality upon which assimilationist passing rests.

The initial formulations of risk in dance still retained this utopian element, one where a new future was always available. By being treated as a source of bad risk, and by surviving and renegotiating the designation of at-risk signaled in the Croce episode, Jones moves into his fourth decade as a choreographer with a different relation to the now pervasive temporality of risk. The regime of accountability, of self-management, of what in actuarial terms are called "defined contributions" (pay as you go for your pension rather 
than await a defined benefit), augured by the neoconservative and neoliberal regimes of the past three decades have entailed a "risk shift" that has profaned the sacred, utopian, modernist conception of the future as a world apart and brought it crashing into the present in the form of a calculus of present decisions and consequences (Hacker 2006). The avalanche of at-risk designation threatens to bury artists as it does schoolchildren, multiculturalists, or those who once would be labeled deviants and marginals under the dull weight of a regime of accountability that need not account for itself. In Jones we see a survival of these wars-not a lone heroic figure but one able to draw upon an enormous portfolio of affiliations and commitments, histories and possibilities. The phantoms of the past are part of present repertories. The ghosts of doubt that haunt so many current progressive tendencies must share the stage with the self-renewing capacity to carry on. This enriched present, leavened with a different sense of passing as what can be carried along, informs two of Jones's more recent works both, from 2006: Another Evening: I Bow Down and Chapel/Chapter.

Bill T. Jones appears in a small red box downstage, his minimal gestures open to narrative. A hardcore rock and roll band, Regained the Heart Condemned, is set upstage behind a large metal fire door. The door slides open and the music periodically blares onto the stage like a game of radio-wave roulette. Jones states, "If we insist on telling the same stories again and again we will become that." Andrea Smith, an actor who has worked with the company for many years, shares the narrative voice, full of biblical references, counting down years at some not too distant point in this third millennium. The words trade with the music for aural focus. We hear intoned, "And it came to pass." Lyrical and somber, piano and violin add to the sonic exchanges. Dancers lead each other through gentle partnerings. Bill T. Jones resumes with an account of his mother Estella's passing in 2002. He shares that she was born in IgI4 and that while they had done many things together, they had never gone to the movies until he took her to see Titanic. She proclaimed, "I know this show. I saw it when I was a child."This recounting of cinematic memory shifts into references to the disaster, to the biblical flood, to calls and responses of "God moved on the water," to Jones calling out his dancers one by one to "c'mon," naming them in the midst of their movement. Dancing floods the stage, alternating between virtuosic solos and unison fields of full-bodied dance, between delicate partnerings where one performer traces the outline of another's body using his/her own limbs as a marker. Andrea Wood offers a transculturation of disaster: "if disaster is the lifeblood of change, why haven't changes been made?"

The luscious movement continues while the religious back drop changes. Wood intones to Buddha, "I bow down," and he is joined in monstrous echo by the lead singer of the rock band, seemingly able to explode the microphone with an eerie gravely voice. Now the counterpoint is with a sitar player seated across the stage from the violinist, providing both spatial and musical triangulation to the soundscape. Jones alone is dressed in black and uses small gestures that orchestrate massive movements of the company onstage, who move like great cumulus clouds in leaps and jumps. Jones returns to his recollections of his mother. He visited her in the hospital. At eighty-eight she could barely recognize him. She spoke little but could sing. She did so when one of her great-grandchildren was placed 
on her chest and began to root and nestle. He adds reflectively, "if you're lucky you get to play all the parts ... you become the story that you tell over and over again." He resumes counting in somber tones picking up with the numbers in a proximate future, adding "A.D." to 2,047 to make it clear that these reference a passing of time in our midst.

Jones has transformed the time and space of performance into a great economic engine, an economy that accumulates stories, movements, cultural references, musical styles, and differences in scale and temporality. The plentitude that passes through the company is transmitted to the audience as well. The iterations of materials in so many different registers invite a work of assemblage by which those in attendance build their own investments and portfolio. The initial counting acts as a kind of historic metronome where time moves but is also compressed within the space of performance. The legacy of Jones's own forebears, the power of storytelling as a communal bond, is turned back upon them to narrate his mother's own passing but also her movement into the space of performance as a living resource for her son's generative creativity. The archeology of loss, of parent, lover, victims of drownings near and distant offers humility to the survivors but also an ensemble of prospects for living on with what has passed. Prior circumstances of disappearance, of amnesia, are through performance allowed to return without resolution. The private, the intimate, the personal, the unspeakable faith are not hushed in shame but form the basis for these public acts. Set in a future made present, the piece begins and ends in another metric of time that is delivered into the liveness of the theatrical experience. Jones sustains his roles as soloist and choreographer through collaborations that are both durable and transitory. Regained the Heart Condemned is both on stage and off, connected and separated, in dialogue and sonic opposition and still interwoven into the piece. Passing is now transformed from so many minuscule humiliations and small sacrifices to be devoured by a banal middleness to a resilience in multiplicity, a capacity to endure detractors and affirm that which allows life to come to pass.

The recent work of Bill T. Jones has made it difficult to sustain the claims of retreat to the formal that had characterized the late-rggos critical reception of his work. John Rockwell, critic for the New York Times, wrote of ChapelChapter on December 7, 2006, "Rarely has [Mr. Jones] been better able to sublimate his wide ranging political, social and moral concerns into art. Rarely has the strength of that art made his vision express itself more purely." "Sublimate" has multiple meanings-in common parlance it refers to what is exalted, elevated, and refined. In psychoanalytic terms it is the redirection of sexual energies into more socially accepted uses. Given Jones's critical reception, the double entendre must be read with due irony. The elevation of politics into art makes the critique socially acceptable. While Anotber Evening premiered in a large proscenium theater (the Skirball Theater at New York University seats 860) and provided some distance with which to regard the spectacle on offer, Chapel/Chapter debuted in a much more intimate environment, a pumping station recently converted into a theater at New York's City College. Arrayed around a rectangular space, the audience could practically touch the performers-who at times sat among the spectators. The hall is draped in red curtains, while on the stage is a white floor in the shape of a large chapel window, divided into rectangular panes with a domed top. Words, images, and maps are projected onto 
the floor, often moving across it as do the dancers. The messages move as adroitly as the messengers, for the performers tell the three stories or chapters that interlace the piece. The sense of being at the lip of the stage/screen with so much going by can be at once kinesthetically riveting and vertiginous. The various projections can achieve the illusion of verticality as if one is sitting at the edge of a window about to fall in.

Chapel/Chapter opens with the company milling about the stage. Many have their eyes closed as a few serve as guides to keep them from stumbling into one another or into the abyss of the audience. The guides, singing in full modal tones that evoke cathedral acoustics, wear rich blue tunics and leggings, while a few are dressed in bright orange jumpsuits that prisoners wear. The dancers depart to leave one orange-garbed figure, Charles Scott, at the base of the chapel window. He is spread out on the ground in the shape of a crucifix and is soon joined by another dancer, Erick Montes, who mirrors Scott head-to-head. The image of a red chair floats by. A voice-over tells of two boys in camp during the summer of 1988 . While the men begin a rolling duet, gentling partnering one another, we hear that the two boys slipped out of their bunks to go into the woods and watch the sun rise. Something happens, we're not told what, but the narrator says he slipped quietly back into bed and didn't tell anyone what happened that day for another eighteen years. The second story is introduced with a child singing and the image of hopscotch squares projected on the stage with a butterfly flitting across. A dancer hops across as we hear, "It was an accident."

The third chapter is also framed as a game, this one the Soto family-Mr. and Mrs. Soto, daughter Josephine, son Junior, and dog-introduced by name to a jaunty tune that leads them into a game of charades. As one family member forms abstract letters on the floor with her whole body, an offstage voice announces the letters and the rest of the family shouts out the words to form phrases like "the road to hell is paved with yellow brick" or "good intentions." The phrases run rapidly by on the floor in two columns of large block letters. The family bliss is sundered by an inquisitorial female voice asking calmly for more particular information. We hear now that on January 15, 1974, a man entered the Soto family residence and killed all inside. A street map is projected, its large scale showing just a few blocks where the events are described in detail. Wen-Chung Len dances the part of the murderer in the moment, while the inquest transpires between the judge and confessed criminal as a voiceover. While we hear the grisly details of forced entry, the lack of planning, and the tying up and murdering of each family member, Len dances each to their death in near-pantomimic ritual. While the murder has a scripted televisual feel, the calm, semidetached voice of the criminal sounds bemused as he relays the challenges to consecrating the acts. He reports his motive as "fantasy, sexual fantasy" and claims "I was wanted" and the Sotos "were selected" as if by some inexorable act of fate. He exhibits some sympathy in the midst of pathos, placing a pillow under Mr. Soto's head and adjusting his bonds so as to make his victim as comfortable as he could. He strangles Mrs. Soto but she doesn't die and gets up again to rescue her children. The murderer confesses that he had never strangled anyone before and didn't know how much pressure to apply. Mr. Soto managed to open a hole in the plastic bag over his head. This had to be replaced. Mrs. Soto needed to be strangled again. The technique of horror was 
imperfect. The job was completed hastily, but the murderer was able to leave by the front door, taking the keys to the family car and driving away. The words of confession appear on the ground that had just been the scene of death. The only survivor, the family dog (Erick Montes) who was put out when the crime began, howls piercingly.

From the violent floor work of the serial strangulation, we return momentarily to the first chapter with the two eleven year olds in camp. They roll caringly over one another, their touch seemingly safe, their weight freely given. Over several interspersed episodes, we learn more of the circumstances for the second story. Andrea Smith plays a clearly pained father trying to reconcile himself to his action. He says his daughter was a troubled child who did bad things. She took a cigarette lighter to her brother, she stole yogurt from the refrigerator, she stuck a toy in the computer printer. For these acts, grave and banal, the father would beat her and tell her he loved her, lock her in the bathroom taped to the floor and make her eat cat food until she vomited and used the litter box for a toilet. He agonizes over her refusal to redeem herself. She didn't have to stay locked up, she could have asked for help, he was right outside. "It was an accident. I didn't mean to kill her. I should have taken her to the police precinct and left her." Smith tells this from a chair while the daughter, Maija Garcia, hurls herself at him and is flung off to roll across the floor. A woman stands behind, not intervening in the percussive encounters before her, and at one point dances languidly with Smith. Punches launch more movement, until there is no more. The full company lies in stillness while scores of projected butterflies migrate over them. Garcia is joined by Asli Bulbul in a delicate finger duet, a residue of child's play after the children are gone. The butterfly hands gesturing on their own convey a fragility of isolation.

The first story is the most mysterious because we don't know what took place and can only surmise some traumatizing tragedy is finally completed. The two boys went to a waterfall and watched the light change. Entranced, the narrator doesn't notice that his friend Cameron is in the water below him. Just as he considers whether to attempt a rescue, Cameron calmly releases himself into the current, gently turns himself over and drifts over the waterfall. The belated witness joins together with the other tales that now mix in fragmented accounts. The dog again howls plaintively, alone. The blending chapters are intoned as a prayer with multiple echoes, interspersed with the directives of the shepherd-_deliver us," "all rise," "this is the way."The company performs an accumulated movement of open palm gestures. They dance in place while the various stories are sung. One final unanticipated chapter is added to the narrative. Through the thick weave of fragments from all that has been witnessed we hear distinctly that "four marines are carried out in a white box with white flowers." They are greeted by an "army" of reporters. "All gone." The sound of cameras clicking accompanies an image of the verdant earth moving across the stage until it shrinks from sight. The sounds of chapel bells, many of them clanging, fill an empty stage. The two in orange jumpers resume their pose of double crucifixion, laid out on the blank white chapel windows. Chapters no more.

Intimacy affords no sanctuary. Sanctuary holds no safety. So much to witness. So many witnesses. Chapel/Chapter demands of its viewers a willingness to stay close to that which is difficult to witness even if it is glorious to see. It plays with our dual desire 
to flinch, to turn away at the queasy horror of catastrophe and the voyeuristic appetite for more. The piece installs its audience in a multiplex of domestic terror and asks them to stay with the corpses to see what might again rise. It releases secrets too horrible to tell from their stately silence and breaks down the partitions among harrowing acts that would deny reflection on the context they share and the common agency they join. It is a dance that refuses to be a mere object, a victim in the domestic culture wars that would incarcerate artists within esthetic obligations that can make no purchase on the world that is their lifeblood. The dance violates that purported innocence. It weaves its trio of stories into a fractal structure of chapters that fold into one another, a house of mirrors that seems to keep us trapped inside, only to be shattered by a reference to the coming home of the dead from adventures overseas. The marines returned in their white boxes counterbalance the various episodes of domestic violation so as to leave us questioning where foreign and domestic part company. Chape/Chapter enacts myriad victimizations but charges the dancers to see the crimes through, not to their resolution or disappearance but to their availability as agonies we can have, address, move with. The dancers need not pass as something else, they need not transcend their own worldliness to contribute to this enlarged capacity to endure a critical reordering, a committed retelling. Though little over an hour in length, the piece leaves all who share its folds and rivulets exhilarated and exhausted. The public is brought into the spectacle, is denied the distance by which spectacle is made other and the labors of dancers a facile enjoyment.

Explicitly inscribed in a sacred space without moorage in a concrete religiosity, ChapeV Chapter nonetheless suggests a reworking of Trinitarian allegory. The father murders his child and blames her sins for this act. The son returns to lay waste to the chosen ones. The holy ghost never comes back and his sacrifice remains inexplicable. This too might be an allegory of the religiosity with mooring in a social ethos that marshaled blame on its victims; it might be dismantling of domestic security and disappearance of a future to compensate for present sacrifice-all of which came to a head with the war on terror. Chapel/Chapter, a marker of the space and time of reckoning, recounting, re-collection, brings us through the chronotope of terror, the inescapable place of lost security, to deliver us past the arresting fear that is a subvention for acquiescence. Instead, it asks that we look again over the past several decades and inquire as to where our domestic tranquility and security may have gone and, ultimately, how we might assemble differently. The dance points to the ways in which our ways of inscribing ourselves in history, in the social, might be reordered. Hence, this is one among the many allegories of passing-of moving through and beyond blockages and impossibilities, foreclosures and occlusions that clot the old byways of assimilationist citizenship. Rather than offering a point-by-point refutation of the protocols by which race, class, and immigrant passing are constructed, the dance shifts the phenomenology of passing and its means of accomplishment from the inside from singularized sameness to a whole field of difference.

Bill T.Jones came of age at a moment when modern concert choreography and dance technique still enjoyed a certain monogamy with respect to one another. In the 1980 os the various technical backgrounds that the dancers brought to the stage provided a dazzling non-assimilationist array. The company we see today seems to be able to do anything

ss


from the floor to the air, from contact roll to ballet lift. Yet these inventories of movement have not passed into anything as singular as the paradigmatic technique that they would replace. Jones's technique is for making dances, for crafting assemblages of artists across media and narrative archives. There is no urgency to replace the unifying functions that modernist technique performed to underwrite the distinct identity of a choreographic authority. Jones appears as a dancer, narrator, character, collaborator, and choreographer in his dances, but he also is an organizer who achieves sublimation as both distillation of the social world in esthetic form and displacement of errant energies into serviceable modes. His is but one career, impressive in its accomplishment and perseverance, but one that speaks to the vitality of work that stays alive to its world. Reading for choreographic agency can render that world alive to its own possibilities to bear, endure, and make otherwise what may seem an impassable moment.

Ours is a moment where enormous wealth has direction without purpose, where unprecedented capacity to intervene betrays reckless indifference, where solutions within reach are withheld to make an example of the problems. It is also a world where for better and for worse small powers keep superior forces at bay, where modest initiatives ripple widely, where the seemingly incidental can be elevated to full throttle. In the space of a single lifetime, a lone career, it is possible to grasp the tailings of a world that has past. The return is impossible, but the techniques of passing on to something else are as urgently required as ever. We can look to dance for so many things, but when it is as richly layered as that of Bill T.Jones, the ability to disclose these means to move on when so much conspires to keep us back remains a resource we cannot do without. As Jones himself has done, we cannot stop inquiring into the agency of dancing, particularly those forms that will appear minor in relation to the great powers for circulating messages and images. But dance shares this predicament with very good company, and there is reason to believe that what might be dismissed as incidental has greater authority than its practitioners might imagine. Why else make so much out of a refusal to see what is challenging or what might redistribute evaluative capacities? War has proliferated as an idea and a practice by moving quickly without a sense of where we want to go and who we want to be when we get there. The allegories of passing described here offer a strategic realignment for dance for politics. Within dance studies, passing may allow for more embrace of multiplicity than the periodizing gestures of modernism and postmodernism have typically allowed if we permit that migration between the manifest content of what we describe and the re-organization of thought that attention to movement makes available. Movement with purpose that has not been assassinated by immediate utility, an ephemerality made to linger, to open a difficult passage, to enlarge the room we have to change ourselves within- not so bad an approximation of what we might want and receive from dance.

\section{Works Cited}

Albright, Ann Cooper. 1997. "Embodying History: Epic Narrative and Cultural Identity in African American Dance." In Choreographing Difference: The Body and Identity in Contemporary Dance, 150-77. Middletown, CT: Wesleyan University Press. 
Daly, Ann. 2002. Critical Gestures: Writing on Dance and Culture. Middletown, CT: Wesleyan University Press.

Dent, Michelle. 2005. “Checking the Time: Bill T. Jones's American Utopia." Drama Review 49 (2): $24-47$.

Foster, Susan L. 2002. Dances That Describe Themselves: The Improvised Choreography of Richard Bull. Middletown, CT: Wesleyan University Press.

Goldman, Danielle. Forthcoming. I Want to be Ready: Improvised Dance as a Practice of Freedom. Ann Arbor: University of Michigan Press.

Hacker, Jacob. 2006. The Great Risk Shift. New York: Oxford University Press.

Jones, Bill T. 1995. Last Night on Earth. New York: Pantheon.

- 2004. "Evoking a Phantom." Available at http://www.billtjones.org/repertory/past/ the_phantom_project/evoking_a_phantom.php.

Martin, Carol. 1996. “High Critics/Low Arts." In Moving Words: Re-writing Dance, edited by Gay Morris, 320-33. New York: Routledge.

Martin, Randy. 1998. "Overreading The Promised Land: Toward a Narrative of Context in Dance." In Critical Moves: Dance Studies in Theory and Politics, 55-I06. Durham, NC: Duke University Press.

Murphy, Jacqueline Shea. I995. "Unrest and Uncle Tom: Bill T. Jones/Arnie Zane Dance Company's Last Supper at Uncle Tom's Cabin/The Promised Land." In Bodies of the Text: Dance as Theory, Literature as Dance, edited by Ellen W. Goellner and Jacqueline Shea Murphy, 8I-ro6. New Brunswick, NJ: Rutgers University Press.

Thompson, M. J. 2005. "Sincerely Dancing: Bill T. Jones Sleight-of-Hand." Drama Review 49 (2): $75-86$.

Zucker, Adam. 2000. Free to Dance: Go for What You Know. Volume 3 of Dance In America. 